Case Report

\title{
Eccrine Nevus Presenting with Umbilical Discharge: A Case Report and Review of the Literature
}

\author{
Farahnaz Bidari-Zerehpoosh, Shahram Sabeti, Farid Arman, and Hania Shakeri
}

Shahid Beheshti University of Medical Sciences, Tehran, Iran

Correspondence should be addressed to Hania Shakeri; hania.shakeri@gmail.com

Received 23 January 2017; Accepted 14 March 2017; Published 21 March 2017

Academic Editor: Ioannis D. Bassukas

Copyright (C) 2017 Farahnaz Bidari-Zerehpoosh et al. This is an open access article distributed under the Creative Commons Attribution License, which permits unrestricted use, distribution, and reproduction in any medium, provided the original work is properly cited.

\begin{abstract}
Eccrine nevus is a rare skin lesion with protean manifestations like hyperhidrosis, discolored nodules, papules, and so forth, which has been reported in various anatomic parts of the body including the forearm, leg, thigh, back, and coccyx. Our patient was a 26year-old male, who presented with increasing colorless and odorless episodic umbilical discharge. First impression for the patient was an umbilical sinus and the patient underwent surgery. Histopathological study revealed the lesion to be an eccrine nevus of the umbilicus. This is the first case of eccrine nevus presenting with umbilical discharge. We recommend that eccrine nevus should be considered as a differential diagnosis for umbilical discharge.
\end{abstract}

\section{Introduction}

Eccrine nevus is a rare skin lesion with protean manifestations [1]. It may present in childhood or adolescence with signs and symptoms such as localized unilateral hyperhidrosis with tendency to involve extremities [2] but has been reported in other anatomic locations as well [1]. It can also present with discolored nodules, papules, and plaques. Hyperhidrosis is the most commonly reported symptom, but it is not always present. Typical histopathology of eccrine nevus includes an increase in the number or size of eccrine coils [3]. Sometimes, ductal hyperplasia and dilation of lumina are notable as well [4]. Two distinct variants of eccrine nevus have been described in the literature. One of them, Eccrine Angiomatous Hamartoma (EAH), contains numerous capillary channels as well as small nerves and sometimes mucin, fatty tissue and pilar structures in between sweat gland coils, which may explain the pressure sensitivity seen in these lesions [2]. The second (often-debated) variant issudoriparousangioma is very similar to $\mathrm{EAH}$, with their only difference being the presence of large caliber vessels and dilated eccrine glands in the former.

\section{Case Report}

We present a 26-year-old male with the chief complaint of umbilical discharge. The problem had started approximately 7 years ago with a gradual increase in the volume and frequency of colorless, odorless, watery-serous discharge. The discharge was recently happening several times a day, with each course lasting 10 to 15 minutes. The patient noted no exacerbating factor for the discharge and no umbilical discoloration or pain. He used to dry this discharge and manipulate the umbilicus with a towel several times a day. The past medical history was insignificant. On physical exam, he had normal vital signs with no fever. In abdominal exam, no erythema, tenderness, or odor was appreciated. Umbilicus was normal looking (Figure 1). However, a deep-seated nodule was found in the umbilicus with the clinical impression of "umbilical sinus." He underwent surgery and excisional biopsy; histopathologic examination revealed a polypoid lesion protruded to umbilicus covered by acanthotic epidermis (Figure 2) with a prominent increase in eccrine coils and dermal fibrosis (Figure 3). There was no increase in vessels and the lesion was ultimately diagnosed as "eccrine nevus." 


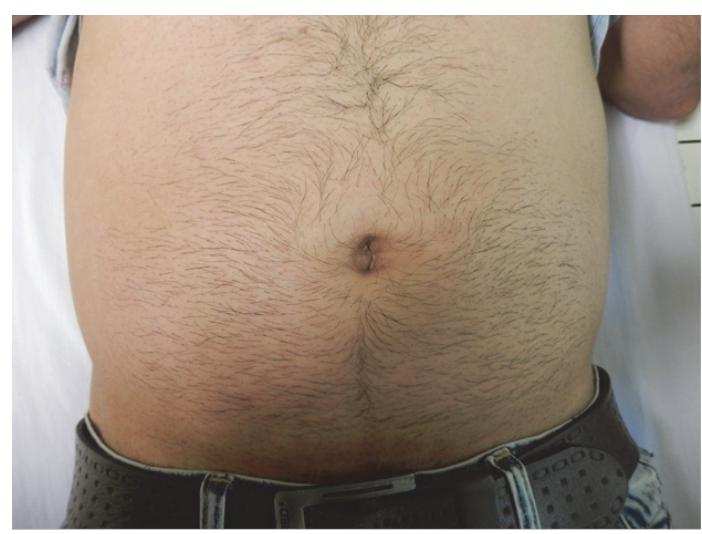

FIgURE 1: Preoperation picture.

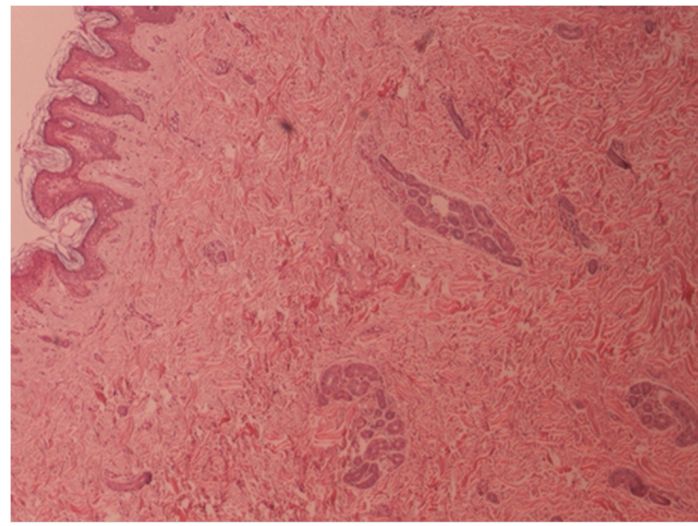

FIgURE 2: Polypoid lesion protruded to umbilicus covered by acanthotic epidermis.

\section{Discussion}

Umbilical discharge can be the result of acquired pathologies, such as pilonidal sinus of umbilicus (suggested as the most common cause in one study), acute omphalitis [5], or congenital anomalies [6], but eccrine nevus and its variants have never been reported as a cause of umbilical discharge.

Eccrine nevus is a rare lesion, with 20 cases reported till 2004, reviewed by Vázquez et al. [4]. Twelve of these cases were female, 3 of them were congenital, and the oldest reported case was 79 years old. The main clinical presentation was hyperhidrosis, followed by linear papules, pigmented/depressed patches, and nodules. The most common site of involvement was forearm. One of the reported cases was an umbilical eccrine nevus in a 32-year-old female presenting with a depressed nodule [4].

Another review by Dr. Tempark and Shwayder [7] included 10 cases of mucinous eccrine nevus (MEN), 6 females and 4 males, with an age spectrum of 4 months to 57 years, and wide distribution of lesions on the leg, thigh, wrist, lower back, and other sites. Four patients presented with hyperhidrosis and 5 of them complained of pain.

Other interesting cases include a 3-month-old male with a congenital midline scalp lesion [8], an 11-year-old female
TABLE 1: Summary of reported cases of eccrine nevus in literature.

\begin{tabular}{lc}
\hline Age & Congenital, 79 years old \\
\hline \multirow{2}{*}{ Gender } & 18 females $(60 \%)$ \\
& 12 males $(40 \%)$ \\
\hline \multirow{2}{*}{ Location } & Upper extremity: $13(43 \%)$ \\
& Lower extremity: $9(30 \%)$ \\
& Trunk: $4(13 \%)$ \\
Presenting signs and symptoms & Head: $4(13 \%)$ \\
& Hyperhidrosis: $12(40 \%)$ \\
& Asymptomatic: $12(40 \%)$ \\
& Tenderness: $5(16 \%)$ \\
\hline
\end{tabular}

* Asymptomatic cases were diagnosed only based on appearance and included papules, patches, and plaques.

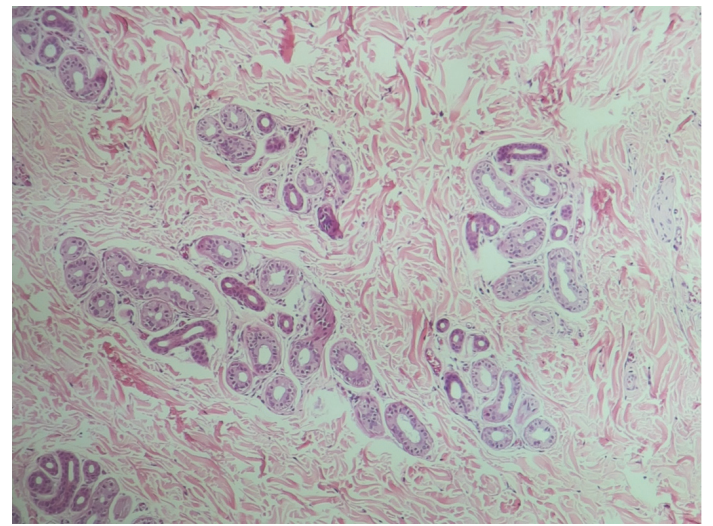

FIGURE 3: Prominent increase in eccrine coils and dermal fibrosis.

with a wide area of hyperhidrosis on the right arm [9], and a 14-month-old male with a slow growing asymptomatic hypopigmented patch on his back since 3 months of age [10]. A summary of known cases is presented in Table 1.

Etiology of eccrine nevus is unknown. The proposed pathogenic factors include congenital defects in embryogenesis, trauma, and stress, but none of them has been proven [7].

Treatment of eccrine nevus can be very challenging. Different methods have been used including surgery [4], antidepressants, anticholinergics, botulinum toxin, iontophoresis, and Glycopyrrolate pad [9].

\section{Conclusion}

To the best of our knowledge, this is the second case of umbilical eccrine nevus and the first case of this kind with the chief compliant of umbilical discharge.

Thus, we recommend that eccrine nevus should be considered as a differential diagnosis of patients presenting with odorless, colorless, watery, nonbloody umbilical discharge, after excluding fistula, sinus, and infectious process. We strongly recommend a biopsy in all cases similar to our case. 


\section{Conflicts of Interest}

The authors declare no conflicts of interest.

\section{References}

[1] D. Weedon, G. Strutton, A. I. Rubin, and D. Weedon, Weedon's Skin Pathology, Elsevier, 2010.

[2] W. F. Lever, F. Walter, and D. E. Elder, Lever's Histopathology of the Skin, Wolters Kluwer Health/Lippincott Williams \& Wilkins, 2009.

[3] E. Calonje and P. H. McKee, McKee's Pathology of the Skin, Elsevier, Saunders, 2012.

[4] M. R. Vázquez, E. Gómez de la Fuente, J. G. A. Fernández, F. J. Martin, J. L. Estebaranz, and F. P. Moraleda, "Eccrine naevus: case report and literature review," Acta Dermato-Venereologica, vol. 82, no. 2, pp. 154-156, 2002.

[5] A. A. El-Bakry, "Discharging umbilicus," Saudi Medical Journal, vol. 23, no. 9, pp. 1099-1100, 2002.

[6] C. M. Molderez, K. B. Wouters, G. B. Bergmans, and G. K. Michiels, "Umbilical discharge: a review of 22 cases," Acta Chirurgica Belgica, vol. 95, no. 3, pp. 166-169, 1995.

[7] T. Tempark and T. Shwayder, "Mucinous eccrine naevus: case report and review of the literature," Clinical and Experimental Dermatology, vol. 38, no. 1, pp. 1-6, 2013.

[8] M. S. Borkin, H. J. Votava, and N. B. Silverberg, "Midline eccrine nevus," Dermatology Online Journal, vol. 17, no. 12, article 4, 2011.

[9] J. Dua and S. Grabczynska, "Eccrine nevus affecting the forearm of an 11-year-old girl successfully controlled with topical glycopyrrolate," Pediatric Dermatology, vol. 31, no. 5, pp. 611-612, 2014.

[10] H. Salama and T. Shwayder, "Eccrine nevus presenting as a hypopigmented patch," Pediatric Dermatology, vol. 25, no. 6, pp. 613-615, 2008. 


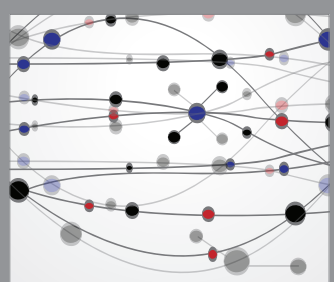

The Scientific World Journal
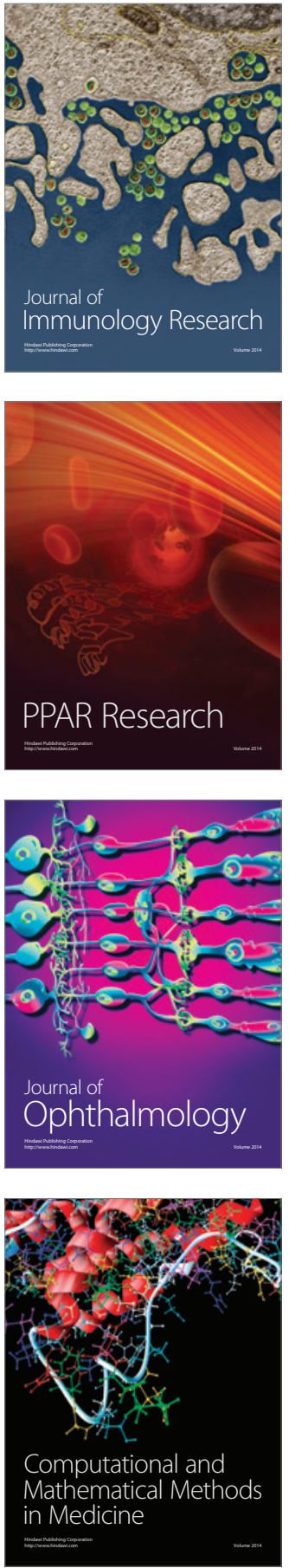

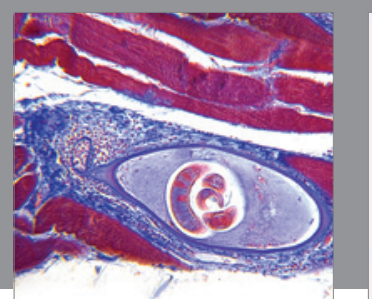

Gastroenterology Research and Practice
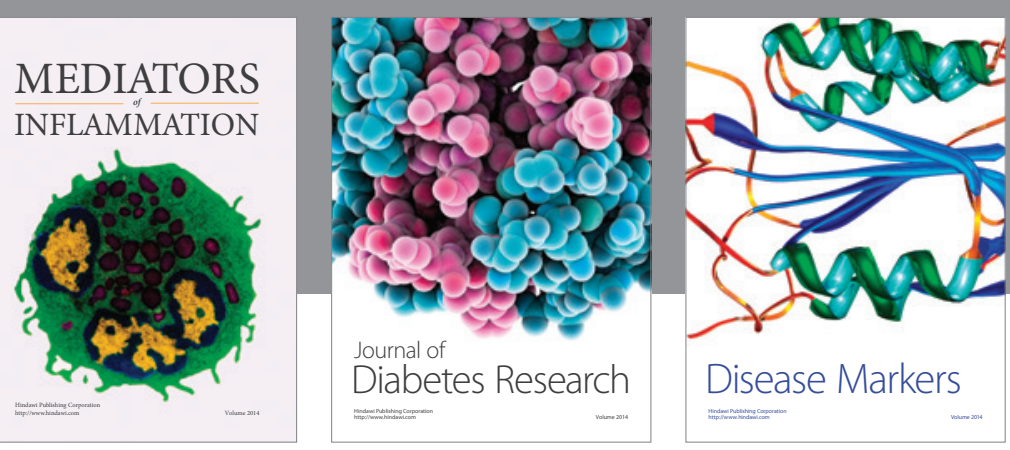

Disease Markers

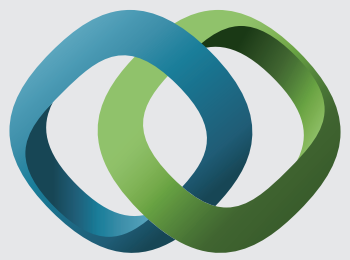

\section{Hindawi}

Submit your manuscripts at

https://www.hindawi.com
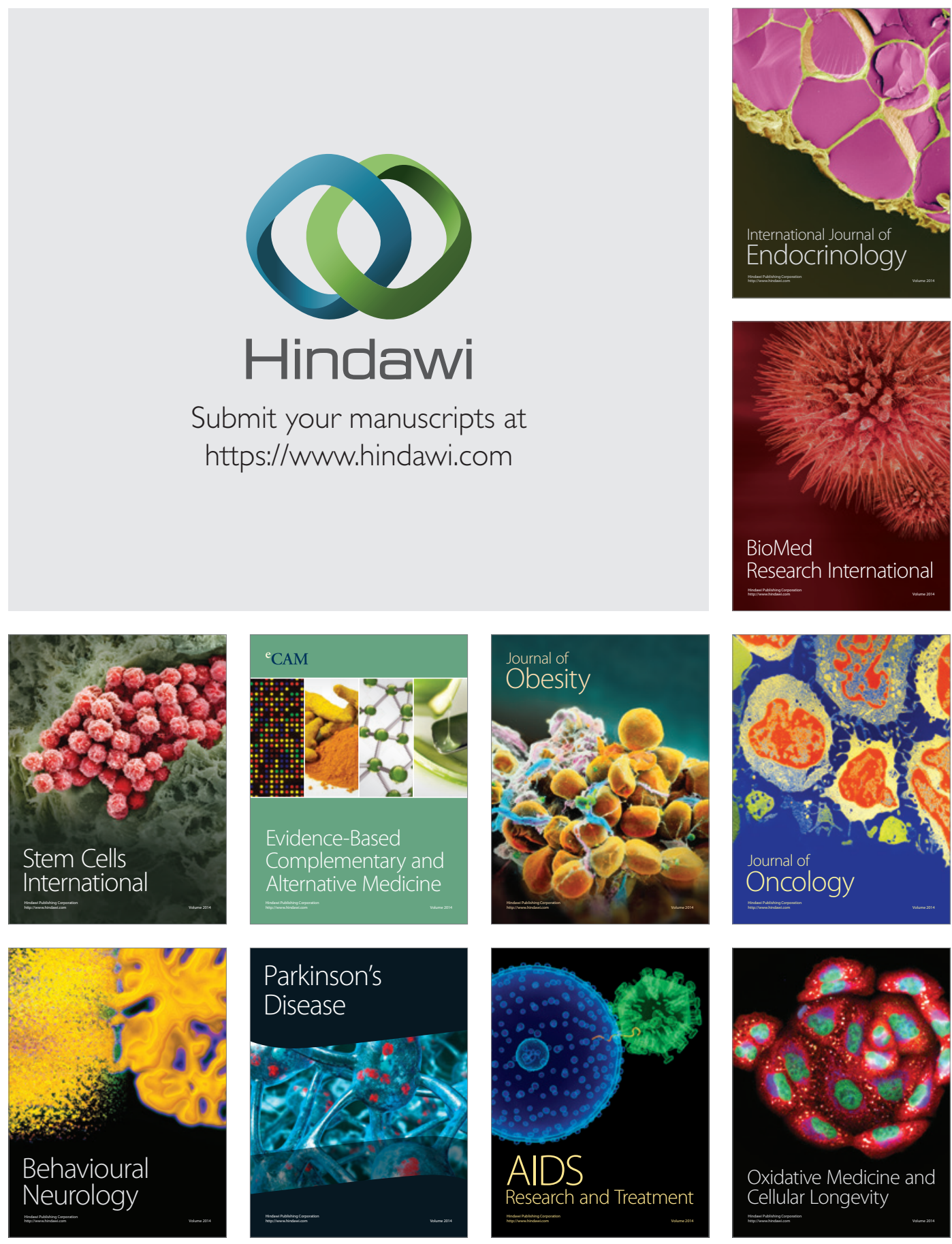